\title{
Evolution of the visibility of scholarly monographs in the academic field
}

\author{
José-Antonio Cordón-García; Javier Merchán-Sánchez-Jara; Almudena Mangas-Vega
}

How to cite this article:

Cordón-García, José-Antonio; Merchán-Sánchez-Jara, Javier; Mangas-Vega, Almudena (2019). "Evolution of the visibility of scholarly monographs in the academic field". El profesional de la información, v. 28, n. 4, e280409.

https://doi.org/10.3145/epi.2019.jul.09

Manuscript received on $30^{\text {th }}$ January 2019 Accepted on $16^{\text {th }}$ July 2019

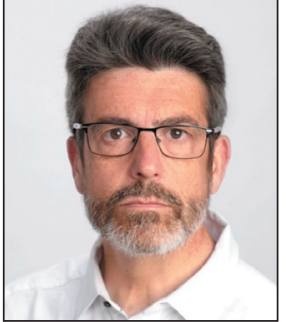

José-Antonio Cordón-García $\bowtie$ https://orcid.org/0000-0002-8569-9417

Universidad de Salamanca

Departamento de Biblioteconomía y

Documentación

Francisco Vitoria, 6-16.

37008 Salamanca, Spain

jcordon@usal.es

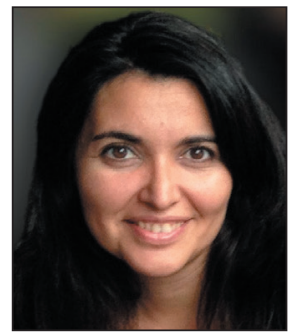

\section{Almudena Mangas-Vega}

https://orcid.org/0000-0002-3464-3624

Universidad de Salamanca

Departamento de Biblioteconomía y

Documentación

Francisco Vitoria, 6-16.

37008 Salamanca, Spain

almumvega@usal.es

\section{Abstract}

Scholarly monographs provide a good example to show the evolution of the impact that digital publishing has had over the last few decades in the transmission and communication of scientific information. On the one hand, in the area of Social Sciences and Humanities relevance in quantitative terms has been undermined, giving prominence to other document types such as research papers published in academic journals. Moreover, their visibility and accessibility have been conditioned by a number of factors that form an intrinsic part of the digital medium itself. Based on these two fundamental premises, this paper aims to analyze only the situation of scholarly monographs in institutional systems for research assessment and tenure, from the perspective of the various proposed requirements regarding accreditation for the different figures of university teaching staff and the request for Spanish recognition of six-year research periods.

\section{Keywords}

Scientific monographs; Academic books; Scholarly books; Research assessment; Research productivity; Research evaluation; Scholarly publishing; Scientific communication; Scholarly communication; Promotion and tenure; Metrics; Spain.

\section{Introduction}

Throughout the history of science, books have been one of the paradigmatic objects for scientific knowledge transmission. For long periods of time, they were the primary vehicle for the dissemination of the new theories and postulates responsible for technical and scientific transformations, as well as being a symbolic reference in the socio-cultural field (Barbier, 2015; Darnton, 2010). In this regard, the writing and publication of monographs ${ }^{1}$ have, for many centuries, invested its authors with the highest levels of prestige and recognition in the public sphere. In some way, this assessment was related to specific impediments restricting access to culture, with its elitist character and limited scope. If culture constituted a sort of private terrain accessible only to certain social elites, access to the editing, publishing and marketing of works' systems only intensified these difficulties and obstacles, usually related to decisions by publishers who arbitrated the production and circulation of works based on a more or less heterogeneous set of scientific, socio-economic and cultural factors (Bourdieu, 2015). 
Electronic publishing in conjunction with specific policies and measures in the second half of the twentieth century achieved a notable evolution towards new heights in the democratization of access to culture. On the one hand, we are witnessing the diversification and opening up to new strata of potential consumers, and on the other, new resources have been created and developed to put out the communication needs of the new knowledge being generated. The development of free communication platforms without pre-established hierarchies, with an unprecedented reduction in costs, are some of the ramifications that digital technologies have had in the exponential growth in text publishing.

In the context of scholarly publishing, these effects led to a considerable growth of the academic community and researchers, which led, in parallel, to an urgent need to publish in order to comply with academic requirements for accreditation and tenure (Bartling; Friesike 2014).

This urgency has meant highly significant transformations in the form and channels of scholarly communication, moving attention to those forms most agile in meeting these needs. This new situation has meant a significant loss in the weight and importance of academic monographs and the institutions that produce them: scholarly publishers and university presses. This new situation is due to the precariousness of the economic means and resources of research libraries, and also to the urgency in the publication deadlines, privileging documentary types that cost less in terms of production, writing and inertia in publication deadlines (Jubb, 2017; Reisz, 2017; Matthews, 2016; Barclay, 2015).

According to the statistics of the Federation of European Publishers, the volume of business attributable to academic books has decreased from $29.4 \%$ in 2006 to $18.5 \%$ in 2017, 11 points less (FEP, 2015; 2018).

An indicator of the loss of weighing of such works in Spain can be seen in the evolution of the average print runs. In 2009, according to statistics released by the Federation of Publishers' Guilds of Spain, the average print run for Social Sciences and Humanities was 2,757 copies; in 2016 the circulation was reduced to 1,452 copies, 47\% less (FGEE, 2011; 2017).

Another indicator can be the number of pages published that, in the area of Social Sciences and Humanities, has gone from an average of 272 pages in 2012 to less than 200 in 2018 (Ministerio de Cultura, 2013; 2018).

Finally, if we look at reading preferences, we can also see a decrease in readers' interest in issues related to Social Sciences and Humanities. The Ministry of Culture of Spain was publishing from 1999 to 2012 the series of statistics Habits of reading and purchase of books in Spain, in which various reading parameters are reported annually in Spain. After an interruption of 5 years, the publication resumed in 2018. When readers were asked about the subject of the last book read, there was a decrease for Social Sciences and Humanities from 14.7\% in 2012 to 9.9\% in 2017 (FGEE, 2013; 2018).

This fact is confirmed, for example, through a study conducted by Digital Science, which showed how the number of monographs, especially in the social sciences, had dropped from accounting for a majority of the contributions in 1992 to only 16\% in 2014 (Hefce, 2016). On the other hand, a very important factor to consider is the weight and relevance granted to each of these two types (the scholarly monograph and the scientific article) in today's accreditation and tenure systems for academic

\section{A study conducted by Digital Science showed how the number of monographs, especially in the social sciences, had dropped from accounting for a majority of the contributions in 1992 to only $16 \%$ in 2014} research. At present, the demand for research competences includes a broad set of needs and activities; among others, we have the following (Valladares et al., 2016):

- Be up-to-date with growing bibliographic information on the increasingly complex topics related to research.

- Be able to understand and digest the rapid technical and methodological advances in their field of work.

- Be creative in the presentation of hypotheses and lines of research.

- Perform experiments, collect data and make measurements.

- Analyze the results and write papers.

- Attend conferences, workshops and national and international scholarly meetings.

- Train and supervise students and researchers, from the youngest and most inexperienced, who are taking on their final degree project or dissertation, to the most demanding post-doctoral researchers with experience in various groups and foreign laboratories.

- Create a research group, manage human resources and foster a productive work environment by combining technicians, students and colleagues, either by physically sharing the laboratory or office space or in virtual networks of online or remote collaboration.

- Positing research projects to compete for increasingly reduced economic resources and to which one's own institution, which is limited to paying salary, will never contribute.

- Be able to weather the storm of economic management and the correct execution of project spending.

- Receive, respond to and counteract audits by a Spanish Ministry of Finance that seems increasingly interested in reducing expenses and recovering items than in the efficiency of the expenditure that is made.

- Address a growing amount of sclerotic administrative work related to reports, minutes, certificates and various form-fiIling that the economic and political crisis has amplified alarmingly. 
- Evaluate whether the scientific papers of other researchers are suitable for publication.

- Evaluate whether doctoral or post-doctoral students are eligible to receive a salary for doing research.

- Evaluate whether the projects of other researchers are eligible to be financed.

- Teach regularly at their university and in other institutions when invited.

Among all these tasks, the permanent and constant need to publish, is without a doubt, the central activity in the academic life of a researcher, and the one requiring the most time and effort, since the success and development of an academic's professional career depends mainly on both a quantitatively and qualitatively favorable assessment. The pressure generated by satisfying a need whose fulfillment is a sine qua non condition to advance in the academic ranks, together with evaluation systems that on many occasions are perceived as unfair or arbitrary, are often at the root of dissatisfaction and unease on the part of the hard-working researcher (Giménez-Toledo, 2016). In this context, it is very important to pay particular attention not only to what is published but where it is published, in which scientific journal or scholarly publisher. This issue is also directly related to the weightings and demands established by the evaluation agencies themselves in order to determine specific academic merits, and has thus become one of the most important elements in explaining the growth in the number of publications by researchers and their distribution in relation to different types of documents (Larivière; Costas, 2016). In this sense there are interesting initiatives such as those developed within the Cost Enressh program through which you can cross-check systems and research tools in the field of social sciences and humanities in several countries.

https://enressh.eu

In some European countries we find that the monographs still carry important weight, especially in Social Sciences and Humanities. Some authors even consider them predominant, for example, in Humanities (Puuska, 2014); However, it cannot be said that the publication patterns of scientific monographs are similar in all European countries, as is the case with publication patterns of scientific articles. (Sivertsen et al., 2014). For example, Verleysen, Ghesquiere and Engels found notable differences between the Flemish and Norwegian cases: while in the first the percentage of monographs did not reach $30 \%$, in the Norwegian case it was around $50 \%$ in Social Sciences and $60 \%$ in Humanities, the authors pointed to the publication selection processes of each of the countries as a possible cause

There is no question that scholarly monographs have lost its centrality in academic communication in favor of other types of transmission, such as articles and conference papers

(Verleysen; Ghesquière; Engels, 2014). Other works on the same line also indicate a clear relationship between the greater or lesser tendency to publish monographs with scientific policies, research output evaluation systems, and the financing processes, in such a way that a scientific policy aimed at publishing in journals indexed in WoS and Scopus can have consequences for publication patterns in Social Sciences and Humanities, with a special negative impact on the publication of monographs and book chapters (Kulczycki; Engels; Nowotniak, 2017; Sivertsen; Larsen, 2012).

Currently, there is no question that scholarly monographs, previously the paradigmatic vehicle for the transmission of scientific knowledge may be losing their main role in academic communication in favor of other types of transmission, such as articles or conference papers. The causes of this are several and vary in kind. In the first place, the demands imposed for the promotion and development of an academic career force scholars and scientists to plan their production in eminently quantitative terms, programming publication strategies that allow them to extend their CV according to the requirements imposed. In contrast, the effort and time invested in producing an academic monograph can in many cases involve the equivalent to several papers, which in addition will be much better valued in the systems of evaluation and tenure, mainly if they are published in impact journals (as journals indexed in the Web of Science Core Collection and in Scopus). Therefore, the patience and effort involved in the preparation of a monograph are not sufficiently rewarded within a system that is increasingly purpose-driven and dedicated to making the CV effective. In addition, the institutions responsible for the production of academic books, i.e. scholarly publishers ${ }^{2}$, do not have quality assessment systems or prestige rankings that allow the impact of the books to be quantitatively computed, as occurs with the rankings of the large databases that index conferences and scholarly journals. On the other hand, the citation dynamics characteristic of scholarly monographs have a certain inertia with respect to the rhythm and immediacy of scholarly papers, and, assuming that the academic relevance and visibility of the research is directly related to the number of citations that it receives, authors go to those systems that provide a faster, immediate and dynamic recognition.

Finally, although at present any research work is likely to find a way to be published, thanks to a large number of available journals and publishers, including the reviled predatory journals, the publishers with the highest level of prestige apply very selective filters, resulting in very high rates of rejection. Nevertheless, even though digital publishing has almost totally colonized the area of scholarly publishing, printed documentation is still holding its own and is still highly relevant. However, printed texts
Scholarly publishers do not have quality assessment systems or prestige rankings that allow to measure the impact of books, as it occurs with the rankings of the large databases that index scholarly journals 
are clearly drifting towards decreasing returns in relation to the number of copies published, as well as editions, both nationally and internationally, as reflected by statistics.

In Spain, these statements are clearly corroborated by the data on domestic publishing from the two primary sources that measure it, the Panorámica de la Edición Española (Panorama of Spanish Publishing) and the Comercio Interior del Libro (Internal Spanish Book Trade), published respectively by the Ministry of Culture and the Federation of Guilds of Publishers. Analy-

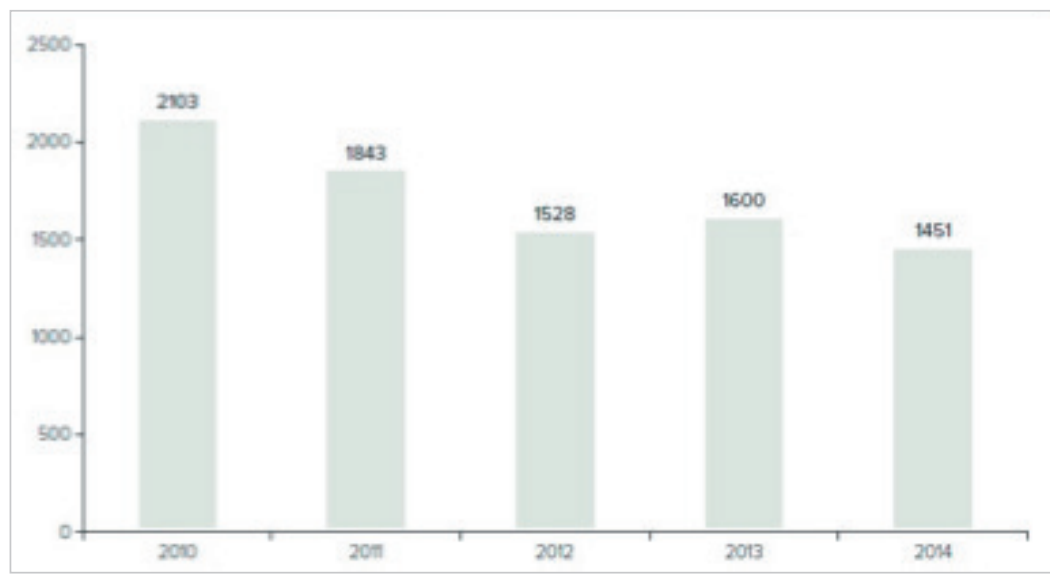

Graph 1. Average print run. Source: Ministerio de Cultura (2014). sing, for example, the last five years that appear in these reports, there were 37,042 titles published in the Social Sciences and Humanities in 2011, but this number decreased to 25,610 by 2016 (Ministerio de Cultura, 2017), signifying approximately a 30\% reduction in production. Similarly, with respect to scientific-technical books, there was a decrease from 14,462 titles to 9,613. Regarding the average print run, the information was taken from the statistics on the publishing of Spain's National Institute of Statistics (INE), and with the entry into force of Act 23/2011, of 29 July, regarding Legal Deposit, as from 2012 modifications were introduced in the field of statistics. One of the changes observed is that it no longer includes information on the number of printed copies and, consequently, on the average print run. The consequence is that, as of 2015, this figure has been omitted, but those of previous years are eloquent (Graph 1).

There has also been a very significant reduction (around 30\%) in the last five years, confirmed both by the Panorámica de la Edición and the Comercio Interior del Libro (2016) as well as the National Institute of Statistics.

These data are even more notorious and significant when analyzing the return rates of the publishing industry in Spain. We speak in this case of one of the indicators that best describes the Spanish situation of the circulation of monographs. This indicator, which is approximately $30 \%$ of the whole, showed a noticeable decrease in the average number of pages published, thus endorsing all the trends that we have been pointing out in relation to the loss of the preponderance of academic monographs.

In light of all the considerations and reflections above, this paper aims to validate the hypothesis that the progressive loss of importance and visibility of books and book chapters in the scholarly production of researchers is directly related to the place that this type of text occupies among the requirements proposed by rating agencies for each of the scientific areas assessed, and by the relative value they hold within them.

Plans for assessing research activity in Spain merge together a significant number of regional, national and international benchmarking and measurement proposals. However, in this context, the role and relevance of the recognised six-year research period (also know as sexenio) are unquestionable. This period-based approach has been developed by the National Committee for the Assessment of Research Activity of Spain (Cneai) ${ }^{3}$ to assess researchers' career development as well as for the granting of certain financial and academic privileges to researchers who obtain favourable evaluations. The request of the sexennium is promoted on an individual basis by each researcher, and the affiliation institutions thereof are limited to give researchers advice on specific issues. The evaluation is carried out by a committee of experts specialized in each knowledge area, which is randomly selected among the university professors who fulfill a series of requirements related to the academic, teaching and research experience; the result of this evaluation is a report certifying whether the requirements are met or not and in this case, is accompanied by a series of comments that motivate the

The progressive loss of importance and visibility of books in the scholarly production of researchers is directly related to the place that this type of text occupies among the requirements proposed by rating agencies for each of the scientific areas assessed, and by the relative value they hold within them

decision (Cabezas-Clavijo; Torres-Salinas, 2015). Following the recent analysis conducted by Giulio Marini (2018), we find three evaluation resources that stand out above the rest: sexennia (research and third duty), five-year (teaching) and accreditation (a mixture of all duties), with the sexennia approach being the one considered best as a means for measuring scientific prestige due to continuous revisions -sic "improvements"-in order to establish a more refined way of measuring, as Marini states. Although there are conflicting positions among experts regarding the value of this type of assessment in the development of research in Spain, such as those of Jiménez-Contreras, De-Moya-Anegón and Delgado-López-Cózar in 2003 (in favour) or those of Osuna, Cruz-Castro and Sanz-Menéndez in 2011 (against), it is not the 
aim of this paper to analyse the contribution of the resource itself, but to study how changes in its norms have been able to affect the use of the monograph (and book chapters) as a documentary type for communicating research knowledge.

Therefore, it is not our intention to blame or hail this way of measuring research activity and its implication in the use of scholarly monographs, but just as when studying other aspects of scientific productivity, such as the contribution of efficiency and technological changes, it is necessary to make an in-depth review of scholarly assessment systems like the Cneai (García-Aracil, 2013), as well as its tools and resources (Jiménez-Contreras, in De-Moya-Anegón and Delgado-López-Cózar, 2003).

As the Leiden Manifesto states -including some examples from Spanish Law- government policies regarding what indicators to use, and how to assess research production may be favouring biases (Hicks et al., 2015). This is the case of the discrimination of local or regional issues or research objects (by encouraging publication in English-language journals) or the distinctive document types in some fields of knowledge, as is the case of monographs for the social sciences and the humanities (Hicks et al., 2015; Wilsdon, 2015).

For all these reasons, this paper aims to answer the following questions:

- What position do the books and book chapters occupy within the requirements proposed by the institutional assessment systems for research in Spain, especially with regard to recognized six-year research periods?

- Are there significant differences and motivations between scholarly areas?

\section{Methodology}

The present work analyses the evolution of the role of books up to the present time in the evaluation systems of scholarly activity in Spain, systematically scrutinizing the explicit requirements in the institutional evaluation ${ }^{4}$ of the sexenios (six-year of research period).

https://www.mecd.gob.es/servicios-al-ciudadano-mecd/catalogo/general/educacion/050920/ficha.html

We start with the requirements proposed in 2011, in order to obtain a perspective of the evolution that has been taking place in the last decade and the recent years of 2016 and $2017^{5}$ with the purpose of observing the changes, if any, that have appeared most recently.

To analyze the sexennium conditions on the use of the monographs in research results, the sexennium must be studied within its framework of action. Using the conceptual framework of the functions of the evaluation systems (distributive, improvement and control) developed by Molas-Gallart (2012) and taking into account their results after the analytical comparison between the United Kingdom and Spain, it can be said that in Spain the evaluation forms part of a broad process of control, whose purpose, rather than emphasizing the distributive and improvement functions, focuses on guaranteeing the responsibility of the researchers. And the sexennium, an independent evaluation tool for research projects, is a clear example of that function.

On the other hand, the peculiar relationship between the six-year term and funding must also be taken into account: according to Hicks (2012) the Spanish sexennia program is a sort of performance-based measure since the researcher who receives a positive evaluation also receives a salary increase. However, taking into account that its use is voluntary and individual and that the institutional funding is generally allocated in the form of block funding based on education metrics, other authors such as Jonkers and Zacharewicz (2016) consider that it should not be considered a form of Research Performance Based Funding (RPBF). The use of the results of the six-year terms also affects the way in which researchers carry out their scholarly activity (including the publication of results).

For such purposes, we use only the data related to the requirements established for obtaining sexennia (six-year terms), in relation to the areas of knowledge (1. Mathematics and Physics, 2. Chemistry, 3. Cellular and Molecular Biology, 4. Biomedical Sciences, 5. Natural Sciences, 6. Engineering and Architecture, 6.1 Mechanical and Production Technologies, 6.2 Communication, Computing and Electronics Engineering, 6.3 Architecture, Civil Engineering, Construction and Urban Planning, 7. Social Sciences, Policies, Behavior and of Education, 8. Economic and Business Sciences, 9. Law and Jurisprudence, 10. History, Geography and Arts, 11. Philosophy, Philology and Linguistics, Field 0. Knowledge Transfer and Innovation) and the parameters established for the different categories according to the types of indications (citations, the prestige of the publisher, number of authors, the position of the author, the number of papers acceptance, or their score).

\section{Results}

\section{Field 1: Mathematics and Physics}

There has been a clear evolution towards a decline in the acceptance of monographs: although journal papers were preferred in 2011, monographs could be included and even the elements to be evaluated were indicated (number of citations, international prestige of the publisher and/or publishers, of the collection in which the work is published and the reviews received in specialized scientific journals). However, in 2016 and 2017 monographs no longer counted as contributions for the purpose of requesting a sexennium, only papers in journals of impact were measured. 


\section{Field 2: Chemistry}

The evolution has followed the same trend: currently, books and book chapters are considered extraordinary contributions and, in any case, only one contribution of this type is admitted among those presented. For a book to be accepted, the international prestige of the publisher, the editors, the collection in which the work is published, and the reviews received in specialized scientific journals is taken into account. However, in 2011, although papers were preferred, the monographs were taken into account.

\section{Field 3: Cellular and Molecular Biology}

As in the previous case, in 2011 the monographs were taken into account although papers were preferred; in the latest calls, only one contribution as a book or chapter of a book was admitted, and, in this field, moreover, its maximum value would be equivalent to that of a scientific paper published in journals of the fourth quartile.

\section{Field 4: Biomedical Sciences}

The possibility of presenting a book or book chapter (whose publisher has to appear in the Scholarly Publishers Indicators $[S P I]^{6}$ or in a collection with CEA-APQ seal) ${ }^{7}$ as a contribution is currently open, but guidelines for obtaining the six-year research term do not contemplate this option, because only papers are counted. Again, there is a trend towards the acceptance of monographs because in 2011 they were considered in the same conditions as in the fields previously described.

\section{Field 5: Natural Sciences}

Books and book chapters are considered extraordinary contributions; no more than one can be counted and even then it has to have been published in prestigious publishers, preferably international ones, with citations, ${ }^{8}$ reviews, and reviews in specialized journals and may be included in specialized bibliographies independent of the author and his or her environment. It is, however, a case with a positive trend, since in the 2011 call -where they were also considered as extraordinary contributions- they were not taken into account in the evaluation.

\section{Field 6: Engineering and Architecture}

This field is divided into three subfields: 6.1, Mechanical and Production Technologies, 6.2 Communication Engineering, Computing and Electronics and 6.3, Architecture, Civil Engineering, Construction and Urban Planning. In this field, the evolution has been slightly different in one of its subfields, despite the fact that, in 2011, the criteria were the same, namely, that monographs would be evaluated (without numerical limitation), based on their unquestionable investigative nature, the number of citations, the international prestige of the publisher, of the editors or of the collection and the reviews in specialized scientific journals. However, at present, we find that in subfield 6.1 only one contribution is admitted, which must be included in specialized bibliographies. In field 6.2, in addition to the same limitations as in field 6.1, a series of books are excluded, among which are those that have to do with teaching, translations or divulgation, among others. However, in field 6.3, in the 2017 call, and as a novelty to previous calls, it is accepted that the contributions may be books or book chapters - without numerical limitations - that meet the conditions indicated above, that is, a prestigious publisher, mainly international, etc. And besides belonging to publishers included in SPI, or belonging to a collection with the CEA-APQ publishing quality seal, other specialized catalogues are also accepted, such as Avery or RIBA for the areas of architecture.

\section{Field 7: Social Sciences, Political Science, Behavioral Science and Education}

Although in 2011 the indications were the same for all areas (books and monographs included in the evaluation without numerical limitation and at the same level as research papers, and assessing the number of citations received, the prestige of the publisher, the editors, the collection in which the work is published, the reviews in specialized scientific journals, and the translations of the work itself to other languages), the cases of acceptance in the most recent calls are quite varied, and depend on each of the thematic areas:

- In the areas of Sociology, Political Science and Administration, Educational Sciences, and Communication, at least two of the five contributions must be papers published in journals. Therefore, only the possibility of including up to 3 books or book chapters is contemplated.

- In the areas of Psychology, at least four of the five contributions must be papers published in journalS, which reduces to one the number of books or book chapters that can be included.

- In the area of Library and Information Science, at least four of the five contributions have to be published papers, and in the last call (2017), these papers also have to be published in journals located in the first two quartiles. Thus, again, the possibility of including monographs is reduced to 1 book or book chapter maximum.

- In all cases, the following are excluded: textbooks, manuals, entries in encyclopedias, reviews, editorial notes, translations, critical prologues, editions of classic texts that do not include extensive preliminary studies or make a significant contribution.

The books and book chapters in this area also have to be published in Spanish publishers that belong to the first quartile of the ranking in the Scholarly Publishers Indicators (SPI), and in the first or second quartile in the case of foreign publishers. The number and nature of the citations received, the reviews and reviews in specialized journals, the collection, and the monograph's translation into other languages will also be taken into account. 
In this field, it is specified that the repeated publication of works in journals or publishers belonging to or associated with the same organization where the applicant conducts her or his research will be unfavorably assessed, as well as the different contributions that are duplicated or are iterative without useful innovation. Having more than one contribution forming part of the same book or journal issue will also be unfavorably assessed. Likewise, when the work shows a high level of self-citations, only the external impact will be considered as an indicator of the impact of the contribution.

In any case, the content of the contributions published in this format should clearly correspond to research results.

\section{Field 8: Economic and Business Sciences}

Books were considered at the same level as scientific papers in the 2011 call, and no numerical limitation was indicated for them. In recent calls, although as a guideline, but a reliable one, a minimum of 2 journal papers is established, and therefore up to 3 contributions are accepted as books or book chapters. These have to fulfill the same conditions previously mentioned, the first quartile of SPI for Spanish publishers, and first or second quartile for foreign publishers. Once again, publications in publishers of the same organization to which the researcher belongs will lead to an unfavorable assessment.

\section{Field 9: Law and Jurisprudence}

Coverage has always been broader. Already in the 2011 call, monographs were accepted (without a limit to their number) and among the elements to be valued were their inclusion in bibliographies independent of the author, that they are the result of research or documented reflection (something that continues in force in the last calls), and the means of dissemination used (without indicating more restrictions). In the current calls, the coverage is still broader than in the rest of the fields in its area of knowledge, since it does not establish minimums for journal papers, and it can thus be deduced that all contributions can be books or book chapters. In the 2016 call, no further details were established regarding the indicators, which take into account the originality, rigour and impact of the contributions and the translation of the work itself into other languages of significance for the international scientific community, although nothing is mentioned about the quality or perceived prestige of the publishers. In 2017, however, they value the fact that the publishers appear in the SPI (although in any quartile), the number and nature of the citations received, the reviews and critical reviews in specialized journals, the collection, the translation into other languages, etc.

In this field, more precise indications are given with respect to book chapters: the contributions in the form of a book chapter must be accompanied by relevant quality indications referring exclusively to the contribution itself and not to the book as a whole, the editor or coordinator or the rest of the authors. In this case, the presentation of contributions in co-authorship is excluded, except for irrefutable proof of their scientific relevance and with the clear explanation of the specific work performed by the requesting co-author.

The repeated publication of works in journals or publishers belonging to or associated with the same organization where the applicant conducts her or his research will be unfavorably assessed.

\section{Field 10: History, Geography and Arts}

In the call for 2011 there were no limits to the number of books or book chapters that could be presented, as long as they were the result of research or documented reflection and they were valued based on the number of citations received, the prestige of the publisher, the editors, the collection in which the work was published, reviews in specialized scholarly journals, the translations of the work itself into other languages, and its inclusion in bibliographies independent of the author and her or his environment. In recent calls, however, differences have been established between the different areas:

- To attain a positive evaluation in the areas of History and Art, at least one of the contributions must be a monographic research book that has international dissemination and reference and meets the requirements indicated in the section (editorial prestige, position occupied in SPI, citations received, etc.); it also admits the combination of a paper in an international journal that satisfies the criteria indicated above and a chapter of a book, in a volume that meets the requirements indicated for them.

- For the area of Geography, two books or book chapters can be contributed, but curiously in this case one of them can be linked to the organization to which the applicant belongs: only a contribution of books or book chapters published by institutional publishers ${ }^{9}$ (including university publishers), or by contributions linked to the same organization where the applicant carries out his or her research, can be positively evaluated, provided that the other criteria are met.

- For the area of Fine Arts, in the 2017 call, no reference is made to any limitations that affect monographs and book chapters.

The criteria for the exclusion of books and book chapters are very extensive, more than in any other area:

a) Textbooks, notes, papers, works, and dictionaries of dissemination or opinion papers.

b) Encyclopaedias (entries or edition).

c) Edition, coordination or translations of texts unless they include preliminary studies or annotations that are the result of original research and represent a valuable contribution to the thematic field.

d) Catalogues that do not include historical or artistic studies. 
e) Transcriptions, if they are not accompanied by critical judgment or historical analysis of the document.

f) Prologues and general introductions which do not exceed the condition of a mere presentation of the prologued work and lack critical interest per se.

g) The minutes of conferences and the like, which do not meet quality criteria comparable to those required for scientific journals and for books and book chapters indicated in point 4.

h) Volumes of tribute proceedings, which do not meet quality criteria comparable to those required for scientific journals and for books and book chapters indicated in point 4.

i) Research projects and the direction of doctoral theses.

j) The reiteration of publications in journals or publishers associated with the same organization where the applicant carries out the research.

ñ) Conceptually and thematically repetitive works, without providing innovation with respect to what has already been published.

In addition, a preventive warning appears on the type of contributions that can be presented: The contributions will be valuable if they represent an advancement of knowledge or methodological innovation, and preference will be given to analytical and comparative studies over purely descriptive ones. Contributions that are repetitions of previous works with those that are conceptually and thematically redundant will not be considered unless they contain innovative elements.

\section{Field 11: Philosophy, Philology and Linguistics}

Books and book chapters are considered, referring to the position held by the publisher in SPI, although in this case it is specified that they must clearly reflect that they are the result of research or of documented reflection.

Research contributions will be considered, as well as critical editions that present a reasoned study of the decisions taken about the text, with the corresponding mention of sources and textual variants and that carry an introductory study that contributes to knowledge. This same criterion will apply to translations. In contrast, simple revisions of texts for publication will not merit this consideration, and the same goes for textbooks or manuals, works of dissemination, encyclopaedias, opinion papers, anthologies or ordinary dictionaries, conference proceedings and tribute proceedings, as well as reviews which do not meet the quality criteria. The repeated publication of works in journals or publishers belonging to or associated with the same body where the applicant conducted the research, or in which the applicant forms part of editorial board or management, will be unfavorably evaluated.

To obtain a positive evaluation: at least one of the contributions must be a monographic research book with international dissemination and reference.

This also includes the possibility of a book chapter; one of the contributions can be a paper in a journal of international impact and the other a book chapter in an international volume.

Thus, the evolution of the consideration of monographs in the evaluation process analyzed can be seen in table 1.

These statements could also be applied to the international context, as many scholars with expertise in the field have stated as much in the scholarly literature (Sivertsen, 2014; Williams et al., 2018).

\section{Conclusions}

From the point of view of the systems for assessing faculty members research output, scientific monographs are little valued in the majority of the scientific areas. This lack of consideration in the scope of accreditation and tenure processes does not correlate with the specialized editorial production that, although it has decreased in general, as shown by the statistics relating to the number of copies published and printed, has not experienced a backward movement that allows speaking of a consolidated trend.

A remarkable difference in the consideration of books and book chapters has been reliably verified in relation to the specific area of knowledge they pertain to, in such a way that we can establish a first categorization between the Sciences and Engineering, the Social Sciences and the Humanities. These three critical divisions represent three clearly differentiated levels of consideration of books and book chapters:

There is a low level of consideration of scholarly monographs in science and engineering, in which books are considered only at the testimonial level and can be dispensable without significant changes in the dynamics of the disciplines that comprise it. In second place we find a medium level of consideration in the Social Sciences, in which monographs are generally admitted as potentially considerable contributions, and whose acceptance is subject to the fulfillment of a series of more or less restrictive requirements such as being published by publishers in the first SPI quartile, of single authorship, not belonging to the same organization to which the author belongs, etc.). Finally, we find a high level of consideration in the disciplines that make up the Humanities. In this third category, there are greater conditions of flexibility, although in all cases the acceptance or not is subject to an extensive set of inclusion and exclusion criteria. 
Table 1. Evolution of the monographs considered in the evaluation process

\begin{tabular}{|c|c|c|c|c|}
\hline Field & Guidelines 2011 & Guidelines 2016 & Guidelines 2017 & Guidelines 2018 \\
\hline Mathematics and Physics & $\begin{array}{l}\text { Papers preferred } \\
\text { but books consi- } \\
\text { dered }\end{array}$ & Not considered & Not considered & Not considered \\
\hline Chemistry & $\begin{array}{l}\text { Papers preferred } \\
\text { but books consi- } \\
\text { dered }\end{array}$ & $\begin{array}{l}\text { Not considered } \\
\text { Extraordinary research consi- } \\
\text { dered and, in any case, only } \\
\text { one is accepted. }\end{array}$ & $\begin{array}{l}\text { Not considered } \\
\text { Extraordinary research } \\
\text { considered and, in } \\
\text { any case, only one is } \\
\text { accepted. }\end{array}$ & $\begin{array}{l}\text { Not considered } \\
\text { Extraordinary research } \\
\text { considered and, in any case, } \\
\text { only one is accepted. }\end{array}$ \\
\hline Cellular and Molecular Biology & $\begin{array}{l}\text { Papers preferred } \\
\text { but books consi- } \\
\text { dered }\end{array}$ & $\begin{array}{l}\text { Extraordinary research works } \\
\text { considered and, in any case, } \\
\text { only one is accepted. }\end{array}$ & $\begin{array}{l}\text { Máx. } 1 \text { and its value = Q4 } \\
\text { paper }\end{array}$ & $\begin{array}{l}\text { Máx. } 1 \text { and its value = Q4 } \\
\text { paper }\end{array}$ \\
\hline Biomedical Sciences & Papers preferred & Not considered & Not considered & Not considered \\
\hline Natural Sciences & Not considered & $\begin{array}{l}\text { Not considered, Extraordi- } \\
\text { nary research considered } \\
\text { and, in any case, only one is } \\
\text { accepted. }\end{array}$ & $\begin{array}{l}\text { Not considered, Extraor- } \\
\text { dinary research conside- } \\
\text { red and, in any case, only } \\
\text { one is accepted. }\end{array}$ & $\begin{array}{l}\text { Extraordinary research } \\
\text { considered and, in any case, } \\
\text { only one is accepted. }\end{array}$ \\
\hline $\begin{array}{l}\text { Engineering and Architecture } \\
\text { (Mechanical and Production } \\
\text { Technologies) }\end{array}$ & $\begin{array}{l}\text { Considered. } \\
\text { No limits }\end{array}$ & Only 1 publication considered & Max 1 & Max 1 \\
\hline $\begin{array}{l}\text { Engineering and Architecture } \\
\text { (Communication Engineering, } \\
\text { Computer and Electronics) }\end{array}$ & $\begin{array}{l}\text { Considered. } \\
\text { No limits }\end{array}$ & Only 1 publication considered & $\begin{array}{l}\text { Not considered } \\
\text { (only exceptional rele- } \\
\text { vant cases) }\end{array}$ & $\begin{array}{l}\text { Not considered } \\
\text { (only exceptional relevant } \\
\text { cases) }\end{array}$ \\
\hline $\begin{array}{l}\text { Engineering and Architecture } \\
\text { (Architecture, Civil Enginee- } \\
\text { ring, Construction and Urban } \\
\text { Planning) }\end{array}$ & $\begin{array}{l}\text { Considered. } \\
\text { No limits }\end{array}$ & Only 1 publication considered & $\begin{array}{l}\text { Considered. } \\
\text { No limits }\end{array}$ & $\begin{array}{l}\text { Considered. } \\
\text { No limits }\end{array}$ \\
\hline Social Sciences (2016) & $\begin{array}{l}\text { Considered. } \\
\text { No limits }\end{array}$ & $\begin{array}{l}\text { A) Sociology, Political Science, } \\
\text { Education Sciences: max } 3 \\
\text { books or book chapters } \\
\text { B) Psychology and Library and } \\
\text { Information Science: } \max 1 \\
\text { book or book chapter }\end{array}$ & $\begin{array}{l}\text { A) Sociology, Political } \\
\text { Science, Education } \\
\text { Sciences: max } 3 \text { books or } \\
\text { book chapters } \\
\text { B) Psychology and } \\
\text { Library and Information } \\
\text { Science: max } 1 \text { book or } \\
\text { book chapter }\end{array}$ & $\begin{array}{l}\text { A) Sociology, Political Scien- } \\
\text { ce, Education Sciences: max } \\
3 \text { books or book chapters } \\
\text { B) Psychology and Library } \\
\text { and Information Scien- } \\
\text { ce: max } 1 \text { book or book } \\
\text { chapter }\end{array}$ \\
\hline $\begin{array}{l}\text { Economics and Business } \\
\text { Sciences }\end{array}$ & $\begin{array}{l}\text { Considered. } \\
\text { No limits }\end{array}$ & Max 3 books or book chapters & $\begin{array}{l}\text { Max } 3 \text { books or book } \\
\text { chapters }\end{array}$ & $\begin{array}{l}\text { Max } 3 \text { books or book } \\
\text { chapters }\end{array}$ \\
\hline Law and Jurisprudence & $\begin{array}{l}\text { Considered. } \\
\text { No limits }\end{array}$ & $\begin{array}{l}\text { Up to } 5 \text { books or book } \\
\text { chapters }\end{array}$ & Considered. No limits & Considered. No limits \\
\hline \multirow{2}{*}{$\begin{array}{l}\text { History, Geography and Arts } \\
\text { (2016) }\end{array}$} & \multirow{2}{*}{$\begin{array}{l}\text { Considered. No } \\
\text { limits. At least } 1 \\
\text { needed }\end{array}$} & $\begin{array}{l}\text { A) History and Art: min } 1 \\
\text { book. }\end{array}$ & $\begin{array}{l}\text { A) History and Art: } \min \\
1 \text { book. }\end{array}$ & $\begin{array}{l}\text { A) History and Art: } \min 1 \\
\text { book. }\end{array}$ \\
\hline & & $\begin{array}{l}\text { B) Geography: } \max 2 \text { books or } \\
\text { book chapters }\end{array}$ & $\begin{array}{l}\text { B) Geography: } \max 2 \\
\text { books or book chapter }\end{array}$ & $\begin{array}{l}\text { B) Geography: } \max 2 \text { books } \\
\text { or book chapter }\end{array}$ \\
\hline $\begin{array}{l}\text { Philosophy, Philology and } \\
\text { Linguistics. }\end{array}$ & $\begin{array}{l}\text { Considered. } \\
\text { No limits }\end{array}$ & Considered & Considered & Considered. No limits \\
\hline
\end{tabular}

- Antagonistic processes were observed to run in parallel. These involve the general loss of consideration and evaluation of monographs in disciplines related to the Social Sciences, areas where the book has historically been one of the paradigmatic vehicles for the transmission of knowledge, whereas in the natural sciences, where the immediacy of the scientific paper has traditionally been privileged, the door is opened to the consideration of monographs.

- There are significant discrepancies and inequalities between the different fields of research in relation to the weightings given to books and book chapters, as well as to the requirements in general for obtaining the six-year search terms or sexennia. There are no criteria or duly explained motivations to justify the application of one criterion or another. Similarly, there are no clear, concise and motivated references to characterize the concept of national or international publishing prestige, such that intentional quality onstitutes per se an indication of quality to be valued.

- In most cases, co-authorship is systematically penalized, even when it constitutes a widespread practice in almost all scientific areas, often irrevocably due to the demands of the research itself. 
- Publication by publishers of the same institution to which the researcher is attached is also penalized without the possibility of applying compensatory mechanisms that make it possible to highlight the quality of the publication in cases where necessary. This consideration prejudges in an unjustified and predetermined way by presupposing unethical or unacceptable practices within the publishing system, such as the possibility that special privileges will be afforded those in the institution.

- Given the paltry consideration of books and book chapters compared to the effort in time and dedication that they demand, one would expect that they would tend to decline, with the consequences that this will have for the future of scholarly publishers. They will become the refuge either for institutional publishing, in the literal sense of the term, or for new authors, who have no other way to get published, or for the senior authors who no longer have to go through the system of academic evaluation of their research results. This is because researchers have realized that it is more productive for their tenure and academic career development to publish a paper instead of a scholarly monograph given the greater amount of time it takes to produce a book.

- In specific contexts the academic monographs are weighted, establishing a parallel with the ranking system of scholarly journals, the scientific book being weighted by default as a publication assigned to the fourth quartile (Q4) of these rankings without any other consideration as to its scientific relevance, its impact on the community or the prestige of the publisher.

- The constant loss of relevance and value of academic monographs in the evaluation systems of scientific and scholarly activity involves highly significant consequences for the healthy development of research. The systematic privileging of papers and the more synthetic and reductionist forms of communication has a direct effect on such essential issues as the choice of the object of study, the epistemological perspectives adopted in the research and the methodologies and instruments that are used in them. In this regard, research into all those matters in which deep reflection and the particularities of the discourse are a consubstantial element, in favor of proposals more and more orientated to the partial observation of reality, eminently empirical and quantifiable fieldwork and the synthesized expression of results and valuations.

- In the academic publishing community, there has been a certain suspicion about the specific quality assessment systems for academic monographs, which relegate the traditional role of the editor as a quality assurance factor and redirect the landscape towards the more quantitative paradigm created originally for journal papers.

- As has been seen throughout this paper, the status of the monographs is very uneven, depending on their importance in the assessment of the criteria established by the different areas. Adequate functioning of the system would require a real weighing of the weight of the different publications in each of the specialties, in such a way that the evaluation would respond to the effective academic practices, and not to those considered as ideal, often distanced from the prevailing academic reality. For example, in the area of Information and Documentation, the irrelevance of the monographs lacks a foundation in some specialties where the humanistic component continues to be very strong, and in which a good part of the researchers channel their production through the books and chapters of books in prestigious editorials. For all this, it is necessary to reflect in-depth on the nature of the publications to be considered and, above all, on the role of books in the processes of transfer of scientific information.

\section{Notes}

1. For this study, "monograph" refers to scholarly book publications including monographs and papers/chapters in books.

2. Speaking of scientific editors, we refer to both university presses, the main aspect of an institutional or public issue in academia, as private publishers who have specialized collections in any field of knowledge.

3. Cneai is an advisory and evaluation entity of the National Agency for Quality Assessment and Accreditation (Aneca), under the Ministry of Science, Innovation and Universities autonomous agency, and entity responsible for setting evaluation criteria.

4. Literal name of the program.

5. Table 1 also contains the data for 2018 in order to reinforce the analysis carried out in the article

6. Scholarly publishers indicators

http://ilia.cchs.csic.es/SPI

See: Giménez-Toledo, Tejada-Artigas y Mañana-Rodríguez (2012)

7. Sello CEA-APQ:

http://www.selloceaapq.es

8. Book's citations are provided by the applicant who has to inquire through different existing systems, standardized or not, such as Book Citation Index, Google Scholar, Scopus, mainly in a process that is commonly known as quality clues referencing (búsqueda de indicios de calidad).

9. As literally mentioned in the Sexenios assessment guidelines. 


\section{References}

Barbier, Frederic (2015). Historia del libro. Madrid: Alianza. ISBN: 9788491040491

Barclay, Donald A. (2015). "Academic print books are dying. What's the future?". The conversation. Rigor académico, oficio periodístico. University of California.

https://theconversation.com/academic-print-books-are-dying-whats-the-future-46248

Bartling, Sönke; Friesike, Sascha (eds.) (2014). Opening science: The evolving guide on how the internet is changing research, collaboration, and scholarly publishing. Springer. ISBN: 9783319000268 https://doi.org/10.1007/978-3-319-00026-8

Bourdieu, Pierre (2015). Las reglas del arte: génesis y estructura del campo literario. Barcelona: Anagrama. ISBN: 978 8433013975

Cabezas-Clavijo, Álvaro; Torres-Salinas, Daniel (2015). Los sexenios de investigación. Barcelona: Editorial UOC; El profesional de la información. ISBN: 9788490645307

Darnton, Robert (2010). Las razones del libro: futuro, presente y pasado. Madrid: Trama. ISBN: 9788492755363

FEP (2016). European book publishing statistics 2015. Federation of European Publishers. https://fep-fee.eu/European-Book-Publishing-823

FEP (2018). European book publishing statistics 2017. Federation of European Publishers. https://fep-fee.eu/IMG/pdf/european_book_publishing_statistics_2017-2.pdf

FGEE (2011). Comercio interior del libro en España 2011. Madrid: Federación de Gremios de Editores de España. https://www.federacioneditores.org/img/documentos/Comercio_Interior_2011.pdf

FGEE (2013). Hábitos de lectura y compra de libros 2012. Madrid: Federación de Gremios de Editores. https://www.federacioneditores.org/img/documentos/HabitosLecturaCompraLibros2012ESP_310113_1.pdf

FGEE (2018a). Comercio interior del libro en España 2017. Madrid: Federación de Gremios de Editores de España. https://www.federacioneditores.org/img/documentos/comercio_interior_2017.pdf

FGEE (2018b). Hábitos de lectura y compra de libros 2017. Madrid: Federación de Gremios de Editores de España. https://www.federacioneditores.org/img/documentos/HabitosLecturaCompraLibros2017.pdf

García-Aracil, Adela (2013). "Understanding productivity changes in public universities: Evidence from Spain”. Research evaluation, v. 22, n. 5, pp. 351-368.

https://doi.org/10.1093/reseval/rvt009

Giménez-Toledo, Elea (2016). Malestar. Los investigadores ante su evaluación. Madrid: Iberoamericana Vervuert. ISBN: 9788484898184

Giménez-Toledo, Elea; Tejada-Artigas, Carlos; Mañana-Rodríguez, Jorge (2012). “Evaluation of scientific books' publishers in social sciences and humanities: Results of a survey". Research evaluation, v. 22, n. 1, pp. 64-77.

https://doi.org/10.1093/reseval/rvs036

Hefce (2016). Publication patterns in research underpinning impact in REF2014. Digital Science.

https://cutt.ly/y7fc4m

Hicks, Diana (2012). "Performance-based university research funding systems". Research policy, v. 41, n. 2, pp. 251-261. https://doi.org/10.1016/j.respol.2011.09.007

Hicks, Diana; Wouters, Paul; Waltman, Ludo; De-Rijcke, Sarah; Rafols, Ismael (2015). "El Manifiesto de Leiden sobre indicadores de investigación”. Revista iberoamericana de ciencia tecnología y sociedad, v. 10, n. 29, pp. 275-280.

http://www.redalyc.org/articulo.oa? id=92438580012

Jiménez-Contreras, Evaristo; De-Moya-Anegón, Félix; Delgado-López-Cózar, Emilio (2003). “The evolution of research activity in Spain. The impact of the National Commission for the Evaluation of Research Activity (Cneai)". Research policy v. 32, n. 1, pp. 123-142.

https://doi.org/10.1016/S0048-7333(02)00008-2

Jonkers, Koen; Zacharewicz, Thomas (2016). Research performance based funding systems: A comparative assessment. Institute for Prospective Technological Studies, Joint Research Centre.

https://doi.org/10.2760/70120

Jubb, Michael (2017). Academic books and their future. Arts and Humanities Research Council. British Library Academic. Book of the Future Project.

https://academicbookfuture.files.wordpress.com/2017/06/academic-books-and-their-futures_jubb1.pdf 
Kulczycki, Emanuel; Engels, Tim C. E.; Nowotniak, Robert (2017). "Publication patterns in the social sciences and humanities in Flanders and Poland". In: Proceedings of ISSI 2017 Wuhan: 16 ${ }^{\text {th }}$ International Society of Scientometrics and Informetrics Conference, Wuhan, China, 16-29 October 2017, pp. 95-104.

https://www.semanticscholar.org/paper/Publication-patterns-in-the-social-sciences-and-in-Kulczycki-Engels/ ee260bc2395d14a29fa690663f690d0821e76005

Larivière, Vincent; Costas, Rodrigo (2016). "How many is too many? On the relationship between research productivity and impact". PLoS one, v. 11, n. 9, e0162709.

http://journals.plos.org/plosone/paper?id=10.1371/journal.pone.0162709

Marini, Giulio (2018). "Tools of individual evaluation and prestige recognition in Spain: How sexenio 'mints the golden coin of authority'". European journal of higher education, v. 8, n. 2, pp. 201-214.

https://doi.org/10.1080/21568235.2018.1428649

Matthews, David (2016). Academics shun books in favor of journal articles. THE World University Rankings. https://www.timeshighereducation.com/news/academics-shun-books-in-favour-of-journal-articles

Ministerio de Cultura (2013). Panorámica de la edición española de libros 2012. Madrid.

https://www.cegal.es/wp-content/uploads/2016/05/Panorámica-de-la-Edición-Española-de-Libros-2013.pdf

Ministerio de Cultura (2014). Panorámica de la edición española de libros 2013. Madrid: Ministerio de Cultura. https://www.cegal.es/wp-content/uploads/2016/05/Panorámica-de-la-Edición-Española-de-Libros-2013.pdf

Ministerio de Cultura (2017). Panorámica de la edición española de libros 2016. Madrid.

https://www.cegal.es/wp-content/uploads/2017/09/Panorámica-de-la-Edición-Española-de-Libros-2016.pdf

Molas-Gallart, Jordi (2012). "Research governance and the role of evaluation: A comparative study". American journal of evaluation, v. 33, n. 4, pp. 583-598.

https://doi.org/10.1177/1098214012450938

Osuna, Carmen; Cruz-Castro, Laura; Sanz-Menéndez, Luis (2011). "Overturning some assumptions about the effects of evaluation systems on publication performance". Scientometrics, v. 86, pp. 575-592.

https://doi.org/10.1007/s11192-010-0312-7

Puuska, Hanna-Mari (2014). Scholarly publishing patterns in Finland: A comparison of disciplinary groups. Academic Dissertation. Tampere: Tampere University Press.

http://citeseerx.ist.psu.edu/viewdoc/download?doi=10.1.1.1003.9932\&rep=rep1\&type=pdf

Reisz, Matthew (2017). Worst sellers: warning of existential crisis for academic books. THE World University Rankings. https://www.timeshighereducation.com/news/worst-sellers-warning-existential-crisis-academic-books

Sivertsen, Gunnar (2014). "Scholarly publication patterns in the social sciences and humanities and their coverage in Scopus and Web of Science". In: Proceedings of the science and technology indicators conference, pp. 598-604. Universiteit Leiden.

https://www.researchgate.net/publication/297369590_Scholarly_publication_patterns_in_the_social_sciences_and_ humanities_and_their_coverage_in_Scopus_and_Web_of_Science

Sivertsen, Gunnar; Larsen, Birger (2012). "Comprenhensive bibliographic coverage of the social sciences and humanities in a citation index: An empirical analysis of the potential". Scientometrics, v. 91, n. 2, pp. 567-575.

https://doi.org/10.1007/s11192-011-0615-3

Valladares, Fernando; Rodríguez-Gironés, Miguel-Ángel; Magalhaes, Sara; Hortal, Joaquín; Moya, Jordi; Lloret, Francisco (2016). "Comunicación y divulgación, un exigente test de la polivalencia del científico". Ciencia crítica, 21 octubre. http://www.eldiario.es/cienciacritica/Comunicacion_cientifica-divulgacion-cientifico_6_571902806.html

Verleysen, Frederik T.; Ghesquière, Pol; Engels, Tim C. E. (2014). "The objectives, design and selection process of the Flemish Academic Bibliographic Database for the Social Sciences and Humanities (VABB-SHW)". In: Blockmans, Wim; Engwall, Lars; Weaire, Denis. Bibliometrics: Use and abuse in the review of research performance. London: Portland Press, pp. 117-127. ISBN: 9781855781955

https://cutt.ly/y7fAoO

Williams, Geoffrey; Basso, Antonella; Galleron, loana; Lippiello, Tiziana (2018). "More, less or better: The problem of evaluating books in SSH research". In: Bonaccorsi, Andrea (ed.). The evaluation of research in social sciences and humanities, pp. 133-158. Springer, Cham. ISBN: 9783319685540

https://doi.org/10.1007/978-3-319-68554-0_6

Wilsdon, James (2015). The metric tide: Independent review of the role of metrics in research assessment and management. Sage.

https://doi.org/10.4135/9781473978782 